\section{Frog Rod Outer Segments, Investigated by the Freeze-Etching Technique}

\author{
Jürgen Rosenkranz * and Hennig Stieve \\ Institut für Zoologie, Technische Hochschule, Aachen \\ (Z. Naturforschg. 24 b, 1356 [1969] ; eingegangen am 5. Juli 1969)
}

Retinas of light- and dark-adapted frogs (Rana esculcnta) were freeze-etched after MooR's method ${ }^{1}$. To reduce artifacts, no anti-freeze like glycerol was used in most of the experiments, contrary to Moor. The platinum-carbon-replicas produced by freeze-etching were examined by electron microscopy $(40,000 \mathrm{x})$. In most cases the negatives were enlarged three times. Some of the micrographs showed the replicas of rod outer segments broken almost transversally or longitudinally. These transverse and longitudinal fractures of the outer segments were examined and measured on the micrographs.

In the electron micrographs three groups (concerning the diameters) of "elongated structures" interpreted as fibrils (Fäden) were found; these fibrils are regularly arranged. In the light-adapted state, the diameters of the fibrils are:

$d_{1}=(58 \pm 11) \AA, d_{2}=(45 \pm 9) \AA$ and $d_{4}=(39 \pm 9) \AA$ Only the diameter of the $d_{1}$-fibril depended on the state of adaptation and on the chemical preparation before freeze-etching. In the dark-adapted state (da), the diameter of the $d_{1}$-fibril is changed significantly relative to the diameter in the light-adapted state: $d_{1: \mathrm{da}}=(47 \pm 10) \AA$. Outer segments treated with glycerol before freezing (glyz) showed $d_{1}$-fibrils with the diameter $d_{1: \mathrm{glyz}}=(73 \pm 12) \AA$ which is significantly larger than $d_{1}-$ although in the light-adapted state only.

* Die Versuche wurden an Gefrierätzanlagen der Firma Balzers ausgeführt, die Vorversuche im Laboratorium für Elektronenmikroskopie der ETH Zürich und die Hauptversuche zusammen mit der Elektronenmikroskopie (Siemens Elmiskop I) im Institut für Botanik und Mikrobiologie der Kernforschungsanlage Jülich $\mathrm{GmbH}$. Den Leitern dieser Institute, Herrn Prof. Dr. K. MüHlethaler und Herrn Prof. Dr.
In some places of the micrographs fibrils were found crossing each other. The angle between each $d_{1^{-}}$and $d_{2}$-fibril is $\alpha_{1}=(90 \pm 3)^{\circ}$ and $\alpha_{2}=(73 \pm 3)^{\circ}$ between each $d_{1}$ - and $d_{4}$-fibril.

In addition, there were found four groups of approximately "equal distances" between the fibrils. The lengths of these "equal distances" are:

$$
\begin{aligned}
& a_{1}=(370 \pm 34) \AA, \quad a_{2}=(124 \pm 14) \AA, \\
& a_{3}=(302 \pm 21) \AA, \text { and } a_{4}=(45 \pm 6) \AA .
\end{aligned}
$$

The length of these distances do not differ in the light- and dark-adapted state. However, after treatment of the outer segments with glycerol, the distance $a_{3}$ becomes significantly larger in the dark-adapted state compared with the light-adapted one:

$$
a_{3 ; \mathrm{da} ; \mathrm{glyz}}=(340 \pm 23) \AA .
$$

In all cases mentioned above "significant" means that the statement is certain except for a statistical error of 0.1 percent.

In negatively stained outer segments of the frog, fibrils are also recognizable. The diameter of the fibrils in this case is $(85 \pm 20) \AA$.

It is assumed that the outer segments are built up only of these fibrils and cell water.

The micrographs $1.0,2.0$, and $3.0 *$ show three different views of freeze-etched outer segments of the frog. The normals of these views are supposed to stand at right angles to one another. The three different views are interpreted as being caused mainly by three different arrangements of the fibrils.

In a following short communication ${ }^{2}$, a working hypothesis is put foreward which relates these different views to a three dimensional lattice (Raumgitter). It is supposed that the whole outer segment consists of such a lattice. A more detailed presentation of this work is in preparation ${ }^{3}$.

F. Schwanitz, sei hiermit sehr für die Bereitwilligkeit gedankt, mit der sie mich an den Anlagen arbeiten ließen.

* Figs, 1.0, 2.0, and 3.0 see table page 1356 a.

1 H. Moor, J. Ultrastructure Res. 2, 393 [1959].

2 J. Rosenkranz, Z. Naturforschg. 24 b, 1357 [1969].

3 J. Rosenkranz, On the Fine Structure of the Frog's Rod Outer Segments, Observed by the Freeze-Etching Technique, in preparation. 

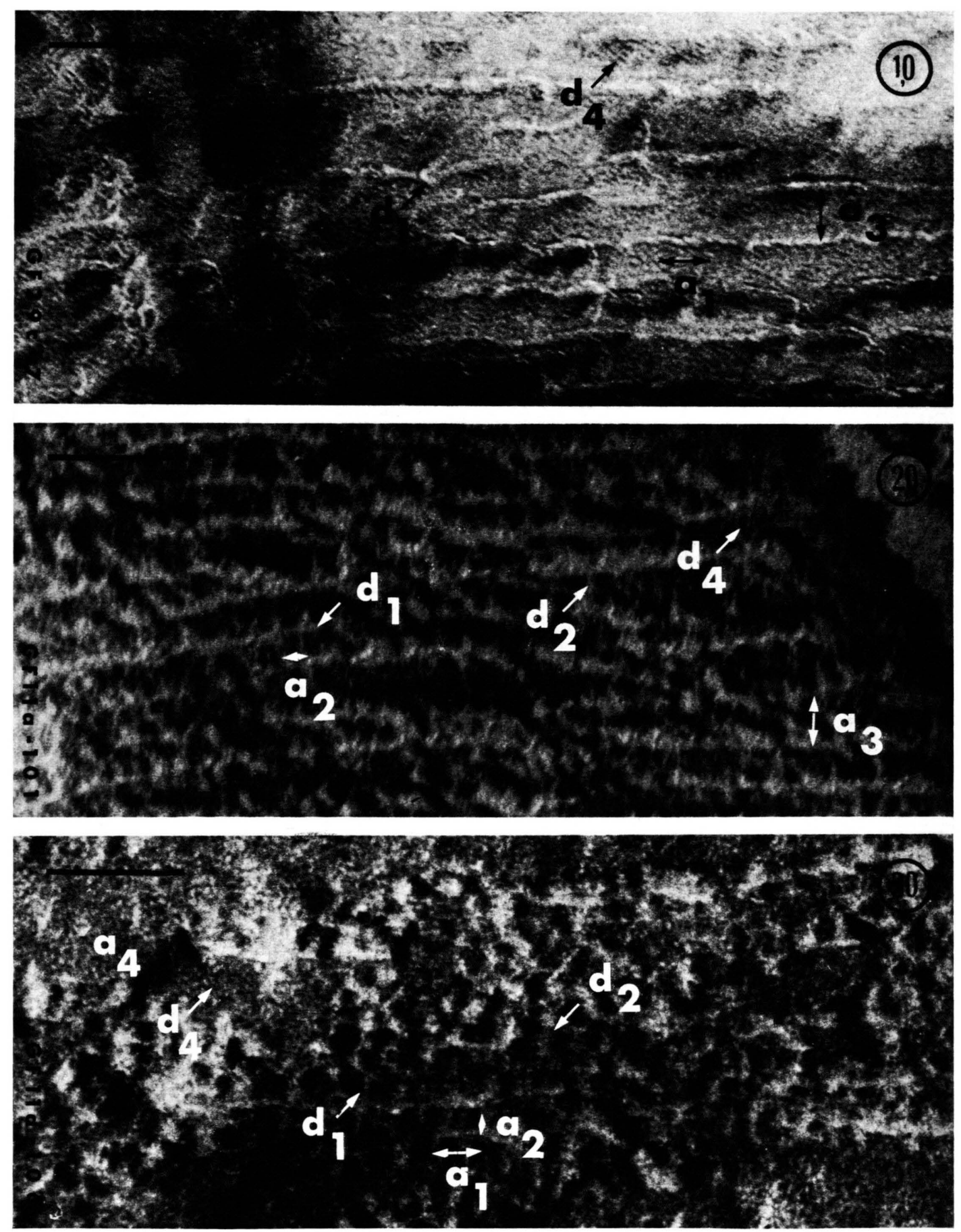

Fig. 1.0. Section of a longitudinally broken rod outer segment of a frog. The line on the above electron micrographs corresponds to a lengths of $1000 \AA$.
Fig. 2.0. Section of a longitudinally broken rod outer segment of a frog. Here the line of vision is changed by about $90^{\circ}$ respectively to the section of fig. 1.0.

Fig. 3.0. Section of an approximately transversally broken rod outer segment of a frog. 
